\title{
FAKTOR-FAKTOR YANG BERHUBUNGAN DENGAN KELUHAN KELELAHAN MATA PADA PEKERJA PENGGUNA KOMPUTER DI BANK X KOTA BANGKO
}

\author{
Novi Berliana ${ }^{1}$, Fauzia Rahmayanti ${ }^{2}$ \\ ${ }^{1,2}$ Program Studi Kesehatan Masyarakat, STIKES Harapan Ibu, Jambi, Indonesia \\ berliananovi831@yahoo.com
}

\begin{abstract}
ABSTRAK
Hasil dari Riset Kesehatan Dasar tahun 2013 menunjukkan bahwa di Indonesia prevalensi severe low vision atau kerusakan fungsi penglihatan dan mempunyai tajam penglihatan kurang dari 6/18 pada umur produktif (15-54 tahun) sebesar 1,49\% dan prevalensi kebutaan sebesar 0,5\%. Prevalensi severe low vision dan kebutaan meningkat pesat pada penduduk sekitar dua sampai tiga kali lipat setiap 10 tahun.Penelitian ini bertujuan untuk mengetahui faktor-faktor yang berhubungan dengan keluhan kelelahan mata pada pengguna komputer di Bank X Kota Bangko. Penelitian ini merupakan penelitian kuantitatif dengan rancangan crossectional. Populasi penelitian ini adalah seluruh pekerja pengguna komputer di Bank X yang berjumlah 42 orang. Penelitian ini dilakukan pada tanggal 18 Mei hingga 9 Juni 2017. Data diperoleh dengan cara pengisian kuesioner, pemeriksaan menggunakan snellen chart, pengukuran jarak dan dianalisis secara univariat dan bivariat dengan uji statistik chi-square. Hasil penelitian menunjukkan bahwa sebagian besar responden mengalami keluhan kelelahan mata sebanyak 29 orang $(80,6 \%)$, responden ada kelainan refraksi sebanyak 21 orang $(58,3 \%)$, sebagian besar responden yang beresiko jarak monitornya sebanyak 16 orang $(44,4 \%)$ dan sebagian besar responden yang beresiko durasi penggunaan komputernya sebanyak 27 orang (75\%). Hasil uji statistik didapatkan ada hubungan kelainan refraksi $p$-value 0,013 , jarak monitor $p$-value 0,011dan durasi penggunaan komputer p-value 0,000, dengan keluhan kelelahan mata pada pengguna komputer di Bank X Kota Bangko.Disarankan kepada pihak bank untuk melakukan pengecekan kesehatan mata secara berkala pada pekerja. Bagi tenaga kerja, bekerja secara ergonomis dan lakukan istirahat mata sehingga dapat mencegah terjadinya keluhan kelelahan mata.
\end{abstract}

Kata kunci : Kelelahan Mata, Kelainan Refraksi, Jarak, Durasi.

Results from the Basic Health Research in 2013 show that in Indonesia the prevalence of severe low vision or visual impairment and has a sharp vision of less than 6/18 in the productive age (15-54 years) of 1.49\% and the prevalence of blindness by $0.5 \%$. The prevalence of severe low vision and blindness increased rapidly in the population about two until three times every 10 years. This study aims to determine the factors associated with complaints of eye fatigue in computer users in Bank X Bangko District.This research is a quantitative research with cross-sectional design. The population of this research is all workers of computer user in Bank X which amounted to 42 people. This study was conducted on May 18 to June 9, 2017. Data were obtained by filling out questionnaires, examination using snellen chart, distance measurement and univariate and bivariate analyzed with chi-square statistical test. The results showed that most of the respondents had complaints of eye fatigue as many as 29 people (80.6\%), respondents there are refractive disorders as many as 21 people (58.3\%), most respondents are at risk of monitor distance of 16 people (44, $4 \%)$ and most of the respondents who are at risk of using computer as much as 27 people (75\%). The result of statistical test showed that there was correlation of refraction ( $p$-value $0,013<0,05)$, monitor distance ( $p$ value $0,011<0,05)$ and duration of computer use ( $p$-value 0,000<0,05), with complaint of eye fatigue on a computer user in Bank X Bangko District. It is advisable to the Bank to conduct periodic eye health checks on workers, conduct. For the workforce, work ergonomically and do eye rest so as to prevent the occurrence of complaints of eye fatigue.

Keywords: Eye Fatigue, Refractive Disorder, Distance, Duration.

\section{PENDAHULUAN}

Hasil dari Riset Kesehatan Dasar tahun 2013 menunjukkan bahwa di Indonesia prevalensi severe low vision atau dalam bahasa Indonesianya merupakan kerusakan fungsi penglihatan dan mempunyai tajam penglihatan kurang dari 6/18 pada umur produktif (15-54 tahun) sebesar $1,49 \%$ dan prevalensi kebutaan sebesar 0,5 $\%$. dengan rata-rata peningkatan sekitar dua sampai tiga kali lipat setiap 10 tahunnya.

Salah satu masalah kesehatan yang ditimbulkan penggunaan komputer yaitu kelelahan 
mata. Kelelahan mata menurut ilmu kedokteran adalah gejala yang diakibatkan oleh upaya berlebihan dari sistem penglihatan yang berada dalam kondisi kurang sempurna untuk memperoleh ketajaman penglihatan. Kelelahan mata timbul sebagai stres intensif pada fungsi-fungsi mata seperti terhadap otot-otot akomodasi pada pekerjaan yang perlu pengamatan secara teliti atau terhadap retina sebagai akibat ketidaktepatan kontras

Keluhan kelelahan mata dipengaruhi oleh beberapa faktor. Faktor-faktor tersebut diantaranya adalah faktor yang karakteristik individu seperti usia dan kelainan refraksi.

Bank $\mathrm{X}$ adalah sebuah perusahaan yang bergerak di bidang jasa perbankan yang bertujuan memberikan pinjaman dan menerima simpanan para nasabah. Pekerja pengguna komputer di Bank $\mathrm{X}$ selalu berinteraksi dan berhadapan dengan layar monitor yaitu mengetik untuk memasukkan data, mengolah data, dan memeriksa data secara teliti dalam jangka waktu yang cukup lama, dengan durasi yang cukup lama tersebut (lebih dari 4 jam) dan pekerjaan yang membutuhkan ketelitian tinggi tentu pekerja akan mengalami suatu resiko pada kesehatan.

Gangguan kesehatan yang ditimbulkan dapat berupa keluhan kelelahan mata. Apabila keluhan tersebut tidak dilakukan pencegahan maka ketajaman penglihatan akan berkurang, menimbulkan penyakit pada mata bahkan dapat menyebabkan kebutaan, sakit kepala, meningkatnya angka kecelakaan, penurunan kualitas kerja karena pekerja kurang fokus sehingga produktivitas kerja menurun sehingga menyebabkan kerugian bagi pekerja dan pihak Bank.

Berdasarkan studi pendahuluan yang dilakukan di Bank X pada bulan November 2016, dari 9 orang pekerja terdapat 7 orang pekerja mengatakan adanya beberapa gejala kelelahan mata. 5 orang mengatakan ada merasakan mata perih, pandangan ganda, sakit kepala belakang dan mata merah dikarenakan berhadapan dengan layar monitor secara terus menerus lebih dari 4 jam dan jarak antara mata dan layar monitor yang beresiko. Penelitian ini bertujuan untuk mengetahui faktorfaktor yang berhubungan dengan keluhan kelelahan mata pada pengguna komputer di Bank X Kota Bangko.

Berdasarkan hal tersebut peneliti tertarik untuk melakukan penelitian mengenai faktor-faktor yang berhubungan dengan keluhan kelelahan mata pada pengguna komputer di Bank X Kota Bangko.

\section{METODE PENELITIAN}

Penelitian ini bersifat kuantitatif dengan menggunakan desain studi crossectional. Penelitian ini menetapkan populasi yaitu karyawan pengguna komputer di Bank X yang berjumlah 42 orang. Jumlah sampel dalam penelitian ditentukan dengan cara total sampling yaitu 42 orang Faktor yang diteliti dalam penelitian ini adalah Kelainan refraksi, Jarak monitor dan durasi penggunaan komputer sebagai variabel independen dengan keluhan kelelahan mata sebagai variabel dependen.

Penelitian ini dilakukan pada tanggal Mei hingga Juni 2017. Data diperoleh dengan cara pengisian kuesioner, pemeriksaan menggunakan snellen chart, pengukuran jarak dan dianalisis secara univariat dan bivariat dengan uji statistik chi-square.

\section{HASIL DAN PEMBAHASAN}

Hasil penelitian menunjukkan bahwa dari 36 responden, sebagian besar responden memiliki keluhan kelelahan mata $29(80,6 \%)$ dan yang tidak ada keluhan kelelahan mata $7(19,4 \%)$. Hasil uji statistik didapatkan ada hubungan kelainan refraksi ( $p$-value 0,013), jarak monitor ( $p$-value 0,011$)$ dan durasi penggunaan komputer ( $p$-value 0,000), dengan keluhan kelelahan mata pada pengguna komputer di Bank X Kota Bangko.

Tabel.1 Distribusi responden berdasarkan keluhan yang dialami pada pekerja pengguna komputer di Bank X Bangko tahun 2017

\begin{tabular}{|c|c|c|c|c|c|c|}
\hline \multirow[t]{3}{*}{ Jenis Keluhan } & \multicolumn{4}{|c|}{ Keluhan Kelelahan Mata } & \multirow{2}{*}{\multicolumn{2}{|c|}{ TOTAL }} \\
\hline & \multicolumn{2}{|c|}{ Ya } & \multicolumn{2}{|c|}{ Tidak } & & \\
\hline & $\mathbf{n}$ & $\%$ & $\mathbf{n}$ & $\%$ & $\mathbf{N}$ & $\%$ \\
\hline Nyeri/terasa berdenyut di sekitar mata & 14 & 38,9 & 22 & 61,1 & 36 & 100 \\
\hline Penglihatan kabur & 9 & 25 & 27 & 75 & 36 & 100 \\
\hline Penglihatan rangkap/ganda & 5 & 13,9 & 31 & 86,1 & 36 & 100 \\
\hline Sulit fokus & 20 & 55,6 & 16 & 44,4 & 36 & 100 \\
\hline Mata perih & 30 & 83,3 & 6 & 16,7 & 36 & 100 \\
\hline Mata merah & 21 & 58,3 & 15 & 41,7 & 36 & 100 \\
\hline Sakit kepala Pusing disertai mual & 7 & 19,4 & 29 & 80,6 & 36 & 100 \\
\hline Bagian kepala belakang sakit & 7 & 19,4 & 29 & 80,6 & 36 & 100 \\
\hline Pundak/bahu sakit & 21 & 58,3 & 15 & 41,7 & 36 & 100 \\
\hline
\end{tabular}


Berdasarkan hasil penelitian menunjukkan bahwa keluhan kelelahan mata pada pekerja pengguna komputer di bank $\mathrm{X}$ yang terbanyak yaitu keluhan mata perih sebanyak 30 responden $(83,3 \%)$ dan terdapat sebanyak 5 responden $(13,9 \%)$ yang mengalami keluhan mata penglihatan rangkap atau ganda

Tabel 2. Analisis univariat Keluhan Kelelahan Mata, Kelainan Refraksi, Jarak monitor, dan Durasi Penggunaan Komputer pada pekerja pengguna komputer di Bank X Kota Bangko Tahun 2017

\begin{tabular}{lll}
\hline \multicolumn{1}{c}{ Variabel } & Frekuensi (n) & Persentase (\%) \\
\hline Keluhan Kelelahan Mata & & \\
Ada & 29 & 80,6 \\
Tidak Ada & 7 & 19,4 \\
Jumlah & 36 & 100 \\
Kelainan Refraksi & & \\
Ada & 21 & 58,3 \\
Tidak Ada & 15 & 41,7 \\
Jumlah & 36 & 100 \\
Jarak Monitor & & \\
Beresiko & 16 & 44,4 \\
Tidak Beresiko & 20 & 55,6 \\
Jumlah & 36 & 100 \\
Durasi Penggunaan & & \\
Beresiko & 27 & 75 \\
Tidak Beresiko & 9 & 25 \\
Jumlah & 36 & 100
\end{tabular}

Hasil penelitian menunjukkan bahwa sebagian besar responden mengalami keluhan kelelahan mata sebanyak 29 orang $(80,6 \%)$, dan sebanyak 7 orang pekerja tidak mengalami keluhan kelelahan mata $(19,4 \%)$. Selanjutnya, terdapat 21 orang pekerja memiliki kelainan refraksi (58\%) dan sebanyak 15 orang tidak memiliki kelainan refraksi (41\%).
Sebagian besar responden yang beresiko dengan jarak monitor sebanyak 16 orang $(44,4 \%)$ dan dan sebanyak 20 orang tidak beresiko (55,6\%). Responden yang beresiko dengan durasi penggunaan komputer sebanyak 27 orang (75\%) dan sebanyak 9 orang tidak beresiko (25\%).

Tabel 3. Hubungan antara Kelainan Refraksi, jarak monitor, durasi penggunaan komputer dengan Keluhan Kelelahan Mata pada pekerja pengguna komputer di Bank X kota Bangko tahun 2017

\begin{tabular}{|c|c|c|c|c|c|c|c|}
\hline \multirow{3}{*}{ Variabel } & \multicolumn{4}{|c|}{ Keluhan Kelelahan Mata } & \multicolumn{2}{|c|}{ Total } & \multirow{3}{*}{ p-value } \\
\hline & \multicolumn{2}{|c|}{ Ada } & \multicolumn{2}{|c|}{ Tidak Ada } & & & \\
\hline & $\mathbf{n}$ & $\%$ & n & $\%$ & $\mathbf{N}$ & $\%$ & \\
\hline \multicolumn{8}{|c|}{ Kelainan Refraksi } \\
\hline Ada & 20 & 95,2 & 1 & 4,8 & 21 & 100,0 & 0,013 \\
\hline Tidak Ada & 9 & 60 & 6 & 40 & 15 & 100,0 & \\
\hline \multicolumn{8}{|l|}{ Jarak Monitor } \\
\hline Beresiko & 16 & 100 & 0 & 0 & 16 & 100,0 & 0,011 \\
\hline Tidak Beresiko & 13 & 65 & 7 & 35 & 20 & 100,0 & \\
\hline \multicolumn{8}{|l|}{ Durasi } \\
\hline \multicolumn{8}{|l|}{ Penggunaan } \\
\hline \multicolumn{8}{|l|}{ Komputer } \\
\hline Berisiko & 26 & 96,3 & 1 & 3,7 & 27 & 100,0 & 0,000 \\
\hline Tidak Berisiko & 3 & 33,3 & 6 & 66,7 & 9 & 100,0 & \\
\hline
\end{tabular}




\section{PEMBAHASAN}

Hubungan Kelainan Refraksi dengan Keluhan Kelelahan Mata

Hasil penelitian menunjukkan distribusi frekuensi pekerja yang memiliki kelainan refraksi 21 orang $(58,3 \%)$ dan yang tidak memiliki kelainan refraksi sebanyak 15 orang pekerja $(41,7 \%)$.

Diketahui dari 21 pekerja yang mengalami kelainan refraksi terdapat 20 pekerja yang mengalami keluhan kelelahan mata dan dari 15 pekerja yang tidak memiliki kelainan refraksi sebanyak 9 pekerja yang mengalami keluhan kelelahan mata. Dari hasil uji statistik diperoleh nilai $\mathrm{p}$-value $=0,013$ yang berarti ada hubungan yang signifikan antara kelainan refraksi dengan keluhan kelelahan mata. Hasil penelitian ini menunjukkan bahwa sebagian besar pekerja di Bank X memiliki kelainan refraksi dan mengalami keluhan kelelahan mata.

Hasil dari penelitian ini selaras dengan penelitian yang dilakukan oleh Septiansyah (2014) yang dilakukan di PT. Duta Astakona Girinda dengan hasil analisis menunjukkan 54\% pekerja yang memiliki kelainan refraksi, hanya 14,8\% pekerja yang tidak mengalami kelelahan mata dan hasil uji statistik diketahui p-value $=0,015$. Penelitian ini juga selaras dengan penelitian Fadhilah (2013) yang menunjukkan adanya hubungan yang bermakna antara kelainan refraksi dengan keluhan kelelahan mata dengan p-value $=0,030$.

Kelainan refraksi adalah keadaan dimana bayangan tegas tidak dibentuk pada retina. Pada kelainan refraksi terjadi ketidakseimbangan sistem optik pada mata sehingga menghasilkan bayangan yang kabur. Seseorang yang memiliki kelainan refraksi tanpa dikoreksi bisa menimbulkan kelelaha mata, sebaliknya seseorang yanng menggunakan komputer lebih dari 4 jam sehari matanya cenderung akan mengalami refraksi.

Pekerja pengguna komputer di Bank X pada saat bekerja fokus tidak hanya pada komputer namun juga teliti melihat dokumen yang akan diketik selain itu ketelitian dalam menggunakan keyboard juga diperhatikan sehingga harus memiliki tingkat fokus yang tinggi agar tidak terjadi kesalahan dalam pengetikan.

Kebanyakan pekerja di Bank X mengaku belum memperhatikan kesehatan mata terlalu rutin seperti pemeriksaan berkala ke dokter mata. Upaya yang sebaiknya dilakukan adalah perlu adanya pengecekan secara rutin dengan Dokter mata agar pekerja mengetahui pentingya kesehatan mata sebelum terjadi kerusakan pada mata. Pekerja yang memiliki kelainan refraksi sebaiknya menghindari menghindari pemakaian lensa kontak karna hal tersebut meningkatkan risiko mata kering sehingga mengakibatkan terjadinya kelelahan mata.

\section{Hubungan Jarak monitor dengan Keluhan Kele lahan Mata}

Dari hasil uji statistik diperoleh nilai p-value $=0,011$ yang berarti ada hubungan yang signifikan antara Jarak Monitor dengan keluhan kelelahan mata

Penelitian ini selaras dengan penelitian Febriana (2012) yang dilakukan pada karyawan bagian administrasi di PT. Indonesia Power Ubp Semarang yang menunjukkan hasil tidak ada hubungan antara Jarak pandang dan usia dengan kelelahan mata. Jarak ergonomis antara layar monitor dengan pengguna komputer berkisar antara $50 \mathrm{~cm}$ sampai dengan $60 \mathrm{~cm}$, apabila jarak monitor tidak ergonomis maka akan beresiko menyebabkan kelelahan.

Menurut Occupational Safety and Health Association (OSHA) pada saat menggunakan komputer jarak antara mata pekerja dengan layar sekurang-kurangnya adalah 200 inch atau sekitar 50 $\mathrm{cm}$. Monitor yang terlalu dekat dapat mengakibatkan mata menjadi tegang, cepat lelah, dan potensi gangguan penglihatan. Jarak ergonomis antara layar monitor dengan pengguna komputer berkisar antara $50 \mathrm{~cm}$ sampai dengan $60 \mathrm{~cm}$.

Pekerja pengguna komputer di Bank X ada yang mengatakan sudah terbiasa dengan jarak monitor yang dekat. Peneliti menyarankan agar pekerja mengatur font size pada monitor agar jarak antara mata dengan monitor terlalu dekat. Selain itu pihak bank dapat memberi peringatan kepada pekerja yang memiliki jarak yang beresiko pada saat bekerja menggunakan komputer karena dapat berdampak negatif bagi kesehatan terutama kesehatan mata.

\section{Hubungan Durasi Penggunaan Komputer dengan Keluhan Kele lahan Mata}

Hasil penelitian menunjukkan terdapat hubungan yang bermakna secara statistik antara durasi penggunaan komputer dengan keluhan kelelahan mata pada pengguna komputer di Bank X dimana nilai $p$ value $=0,000$.

Dari hasil penelitian yang didapatkan pekerja yang bekerja beresiko (dengan durasi penggunaan komputer $>4$ jam) mengalami keluhan kelelahan mata sebanyak $96,3 \%$ dan pekerja yang tidak beresiko yang mengalami Keluhan Kelelahan mata sebanyak $33,3 \%$.

Hasil penelitian ini selaras dengan hasil penelitian yang dilakukan oleh Ivone (2004) mendapatkan pengguna komputer yang mengalami keluhan kelelahan mata sebanyak $88,2 \%$ setelah 4 jam bekerja. Sesuai juga dengan penelitian yang 
dilakukan Dewi (2009) pada operator komputer di Kantor Samsat Palembang tahun 2009 yaitu ada hubungan yang signifikan antara lama penggunaan komputer dengan kelelahan mata dengan nilai $p$ value $=0,028$.

Lamanya penggunaan komputer yang dianjurkan adalah tidak lebih dari empat jam sehari. Bila lebih dari waktu tersebut, mata cenderung mengalami refraksi dan akan mengalami kelelahan mata Seandainya penggunaan dalam tempo lebih dari empat jam itu tak bisa dihindari, frekuensi istirahatnya harus lebih sering (4)

Layar monitor komputer memiliki tingkat radiasi yang tinggi. Jumlah radiasi yang diserap mata berbanding lurus dengan lamanya interaksi dengan layar monitor. Semakin lama berinteraksi dengan layar monitor, kemampuan fisiologis otototot disekitar mata akan mengalami penurunan, akibatnya mata akan mengalami kelelahan.

Pekerjaan di Bank X menuntut pekerja untuk melakukan banyak tugas yang dituntut harus selesai dan mencapai target sehingga tidak dapat ditunda dalam mengerjakannnya, beberapa pekerja ada yang memiliki jam kerja lebih (lembur) sehinga durasi bekerja menjadi lebih lama sesuai pekerjaan dan tuntutan masing-masing jabatan.

Hal yang harus dilakukan pekerja adalah memperbanyak frekuensi istirahat sehingga mata menjadi rileks dan nyaman untuk kembali bekerja, pekerja dapat mengurangi paparan dengan komputer dengan melakukan istirahat mata secara berkala agar ada jeda waktu otot-otot mata untuk beristirahat. Untuk mengurangi resiko kelelahan mata dengan terus menerus berfokus pada layar monitor adalah dengan berpaling dari komputer setidaknya setiap 20 menit dan menutup sebuah objek yang jauh (setidaknya 20 kaki atau 6 meter) selama 20 detik.

Selain itu desain ruangan juga menentukan seperti cat dinding ruangan atau beberapa lukisan yang menyejukkan mata. Untuk mengurangi kejenuhan pekerja dalam mengistirahatkan mata, sebaiknya perlu pengaturan property dalam ruangan pekerja seperti mendesain ulang tata ruang atau cat dinding dan benda-benda yang memiliki warna menyegarkan atau menyejukkan mata, sehingga pekerja dapat mengistirahatkan mata dengan melihat kontras warna yang lebih sejuk. Warna cat dinding ruangan mempengaruhi suasana kerja, warna terang menciptakan lingkungan psikologis yang otimal yaitu berefek menyejukkan untuk kelestarian fungsi mata

\section{KESIMPULAN}

Ada hubungan yang signifikan antara kelainan refraksi dengan keluhan kelelahan mata pada pekerja pengguna komputer di bank X tahun 2017 Ada hubungan yang sigifikan antara jarak monitor dengan keluhan kelelahan mata pada pekerja pengguna komputer di bank X tahun 2017 Ada Hubungan yang signifikan antara durasi penggunaan komputer dengan keluhan kelelahan mata pada pekerja pengguna komputer di Bank X tahun 2017

\section{DAFTAR PUSTAKA}

Fadhilah, Lutfiana. (2013). Faktor-faktor yang berhubungan dengan kelelahan mata pada pengguna komputer di Accounting Group Bank x Jakarta.(skripsi). Universitas Islam Negeri Syarif Hidayatullah Jakarta. (tidak dipublikasikan)

Granjean.(2003). Ergonomics in computerized offices. London: Taylor and francis.

Ilyas, Sidarta. (2014). Penuntun Ilmu Penyakit Mata. Jakarta: Balai Penerbit Fakultas Kedokteran Universitas Indonesia; 2004.

Riset Kesehatan Dasar (2013). Badan Penelitian dan Pengembangan Kesehatan Kementerian Kesehatan RI, 2013.

Wasisto. (2005). Komputer Secara Ergonomis dan Sehat.Dari : http://www.wahana.com .Diakses pada tanggal 20 Januari 2017.

Tarwaka.(2004). Ergonomi Untuk Keselamatan, Kesehatan Kerja dan Produktifitas. Surakarta : Uniba Press.

Roestijawati N. (2007). Sindrom dry eye pada pengguna visual display terminal (VDT). Jurnal Kedokteran Yarsi.vol. 13. No.2, 2007 :205-217

Suma'mur, PK. (2009). Higene Perusahaan Dan Kesehatan Kerja, Jakarta: Sagung Seto. 